\title{
Program Parenting dalam Meningkatkan Pengetahuan dan Penurunan Stres Pengasuhan Orang Tua Berbasis Taman Pendidikan Alquran (TPA)
}

\author{
Aji Winanta ${ }^{1}$, Muhammad Arif Rizqi² ${ }^{2}$ Rifki Febriansah'1, Annisa Krisridwany' \\ 1. Program Studi Farmasi, Fakultas kedokteran dan Ilmu kesehatan, Universitas Muhammadiyah Yogyakarta \\ 2. Program Studi Pendidikan Dokter, Fakultas kedokteran dan Ilmu kesehatan, Universitas Muhammadiyah Yogyakarta \\ Email:ajiwinanta@umy.ac.id \\ DOl: 10.18196/ppm.32.209
}

\begin{abstract}
Abstrak
Perkembangan ilmu pengetahuan dan teknologi sangat memengaruhi kehidupan manusia. Pertukaran informasi yang sangat cepat dapat memberikan dampak yang baik dan buruk. Hal ini dapat memengaruhi sikap dan perilaku anak-anak. Adanya dampak tersebut kita dapat antisipasi dengan menerapkan pendidikan moral sejak dini. Selain orang tua, tempat pendidikan juga memegang peranan dalam membentuk karakter anak. Pengabdian ini bertujuan untuk meningkatkan pemahaman orang tua dan pengelolaan stres pengasuhan dalam mendidik anak melaui program parenting dan Taman Pendidikan Alquran. Program ini dilakukan di Dusun Polowidi, Trimulyo, Sleman, Yogyakarta. Metode pelaksanaan program didahului observasi, tahap perencanaan program, kemudian kegiatan pelaksanaan program menggunakan metode ceramah/diskusi, dan praktik langsung pelaksanaan kegiatan TPA. Pada akhir program, dilakukan evaluasi. Sasaran untuk kegiatan ini adalah ibu-ibu PKK dan anak-anak di Dusun Polowidi. Dari hasil evaluasi program parenting, diketahui bahwa terjadi penurunan rata-rata skor tingkat stres dalam mendidik anak, dari 85,06 menjadi 71,03 (berbeda siginifikan). Program parenting ini menunjukkan bahwa peserta parenting dapat menambah pengetahuan dan menurunkan tingkat stres pengasuhan.
\end{abstract}

Kata kunci: Parenting, pendidikan anak usia dini, stres pengasuhan, Taman Pendidikan Alquran (TPA)

\section{Pendahuluan}

Anak merupakan generasi penerus cita-cita bangsa yang memiliki peran penting dalam menjamin eksistensi bangsa dan negara di masa yang akan datang. Agar mereka kelak mampu memikul tanggung jawab itu, mereka perlu mendapat kesempatan yang seluas-luasnya untuk dapat tumbuh dan berkembang secara optimal, baik fisik, mental, sosial, maupun spiritual. Anak-anak juga berhak atas pemenuhan hak-hak dasarnya, perlindungan dan kehidupan yang sejahtera. Oleh karena itu, segala bentuk tindakan yang kurang baik pada anak perlu dicegah dan diatasi. Anak usia dini menurut the National Association For The Eduction Of Young Children (NAEYC) dan para ahli "Early Childhood" pada umumnya adalah anak masa awal, yakni anak yang sejak lahir sampai dengan usia delapan tahun. Jadi, mulai dari anak itu lahir hingga ia mencapai umur enam tahun, ia akan dikategorikan sebagai anak usia dini.

Perkembangan ilmu pengetahuan dan teknologi sangat memengaruhi kehidupan manusia. Perturakan informasi yang sangat cepat dapat memberikan dampak yang baik dan buruk. Hal ini dapat memengaruhi sikap dan perilaku anak-anak. Fenomena degradasi moral yang sedang terjadi di Indonesia merupakan suatu disintegrasi antara lingkungan, sekolah, dan orang tua. Adanya dampak tersebut kita dapat antisipasi dengan menerapkan pendidikan moral sejak dini, Pola asuh dari orang tua dalam mendidik dan mengasuh anak di dalam keluarga akan sangat berperan penting dalam proses tumbuh kembang anak. Menurut Setiadi (2008), peran keluarga adalah tingkah laku spesifik yang diharapkan oleh seseorang dalam konteks keluarga. Oleh karena itu, peran menggambarkan seperangkat perilaku interpersonal, sifat, kegiatan yang berhubungan dengan individu dalam keluarga yang didasari oleh harapan dan pola perilaku keluarga, kelompok dan masyarakat. Program keayahbundaan (parenting) yang menjadi salah satu program dalam penguatan kehidupan keluarga dan masyarakat Indonesia memberi salah 
satu penguatan dalam kehidupan masyarakat, terutama perkembangan anak usia dini, metode pengasuhan, dan pola komunikasi yang dijalankan oleh sebagian besar masyarakat (Akhyadi dan Mulyono, 2018).

1. Analisis Situasi

Pengabdian masyarakat ini akan dilaksanakan di Dusun Polowidi, Desa Trimulyo, Sleman, Yogyakarta. Secara geografis wilayah ini terletak dekat dengan Gunung Merapi. Warga Dusun Polowidi terdiri atas 127 kepala keluarga (KK). Masyarakat di daerah ini mayoritas sebagai petani dan buruh. Selain itu, juga ada beberapa warga yang bekerja sebagai guru dan berwiraswasta. Kondisi ekonomi rata-tata menengah ke bawah. Tingkat pendidikan masyarakat di daerah ini tidak terlalu tinggi. Hanya ada beberapa saja yang melanjutkan ke perguruan tinggi.

Akses jalan menuju Dusun Polowidi cukup mudah karena dekat dengan jalan utama. Jalan utama di dusun sudah beraspal dan akses menuju rumah-rumah warga sudah berpaving. Mayoritas warga beragama Islam, hanya kurang dari 10 warga di yang beragama nonmuslim. Terdapat satu masjid kecil di tengah-tengah dusun yang menjadi tempat untuk beribadah warga di Dusun Polowidi. Akan tetapi, belum banyak warga yang rutin beribadah salat di masjid. Kegiatan masyarakat di masjid juga belum terlalu banyak. Kegiatan yang rutin di lakukan yaitu "Yasinan" yang diadakan setiap kamis malam. Tidak ada kegiatan di masjid yang melibatkan anak-anak. Di Dusun Polowidi juga belum ada TPA yang dapat dijadikan wadah anak-anak untuk belajar Alquran. Di bidang kesehatan, masih banyak warga yang belum paham tentang penggunaan dan penyimanan obat-obatan. Pentingnya kesehatan untuk keluarga juga menjadi salah satu dasar pentingnya dilaksanaan kegiatan ini.

\section{Metode Pelaksanaan}

\section{a. Program Parenting Keluarga}

Program parenting ditargetkan kepada ibu-ibu PKK yang ada di Dusun Polowidi. Pelaksanaan parenting dilakukan dengan cara penyuluhan kepada warga yang dilakukan selama lima kali pertemuan. Proses awal dilakukan observasi terkait kondisi warga. Selanjutnya, dilakukan pretest (tes awal) untuk mengetahui pengetahuan dan pemahaman awal dari warga terkait cara mendidik anak dan pemahaman kesehatan keluarga. Setelah itu, dilakukan penyuluhan oleh ahli / berkompeten pada bidang parenting dan kesehatan. Penyuluhan dilakukan satu bulan sekali sesuai dengan teman yang disepakati. Lamanya penyuluhan adalah tiga jam yang di dalamnya terdapat diskusi kecil terkait permasalahan yang dialami.

Untuk evaluasi program parenting, dilakukan pada akhir penyuluhan dan dilakukan setelah program terlaksana. Evaluasi berupa post test dan kelanjutan program kegiatan dilakukan terhadap ibu-ibu PKK di Dusun Polowidi.

\section{b. Taman Pendidikan Alquran}

Taman Pendidikan Alquran didirikan di Dusun Polowidi. Pelaksanaan TPA dilakukan di Masjid Darul Huda yang terletak di lokasi mitra dan bekerja sama dengan takmir masjid setempat. Tahap awal dari program ini adalah observasi terkait kebutuhan operasional dari pelaksanaan TPA. Selanjutnya, dilakukan sosialisasi kepada warga supaya mengajak anakanak di dusun tersebut untuk ikut serta pada kegiatan TPA. Untuk permulaan, akan dilakukan TOT kepada takmir masjid mengoordinasikan proses pelaksanaan TPA. Kegiatan TPA dilakukan seminggu satu kali untuk awal pelaksanaan. Dalam proses pelaksaan nantinya, minimal aka nada satu orang pembimbing. Selain itu, juga akan dilakukan pembingan kepada remaja masjid agar dapat menjadi guru atau pembimbing TPA. Evaluasi kegiatan dilakukan setiap satu bulan sekali melalui observasi langsung terhadap kegiatan 
dan capaian keberhasilan kegiatan ini, yaitu kontinuitas program TPA ketika pelaksanaan program sudah selesai.

\begin{tabular}{|c|c|c|c|}
\hline No & Metode Pelaksanaan & Capaian Kegiatan & Proses Evaluasi \\
\hline \multicolumn{4}{|c|}{ Program Parenting Keluarga } \\
\hline 1 & Sosialisasi Kegiatan & $\begin{array}{l}\text { Masyarakat mengetahui } \\
\text { adanya kegiatan program } \\
\text { parenting dan TPA }\end{array}$ & $\begin{array}{l}\text { Berapa banyak } \\
\text { masyarakat yang hadir }\end{array}$ \\
\hline 2 & $\begin{array}{l}\text { Penyuluhan Parenting } \\
\text { Penyuluhan yang dilakukan oleh psikolog tentang } \\
\text { teori-teori parenting yang sesuai dengan cara } \\
\text { pendidik anak menurut Islam. Penyuluhan diberikan } \\
\text { kepada ibu-ibu PKK }\end{array}$ & $\begin{array}{l}\text { Pemahaman Ibu-ibu PKK } \\
\text { terkait teori dan cara } \\
\text { mendidik anak yang baik. }\end{array}$ & $\begin{array}{lr}\text { Kuisioner } & \text { evaluasi } \\
\text { pemahaman rang } \\
\text { diberikan sebelum dan } \\
\text { sesudah penyuluhan } \\
\text { serta pengeloaan tingkat } \\
\text { stress mengasuh anak }\end{array}$ \\
\hline \multicolumn{4}{|c|}{ Taman Pendidikan Al-Quran } \\
\hline No & Metode pelaksanaan & Capaian Kegiatan & Evaluasi \\
\hline 1 & Observasi Lingkungan & $\begin{array}{lr}\text { Diperolehnya } & \text { data } \\
\text { kebutuhan } & \text { dan } \\
\text { permasalahan } & \text { dalam } \\
\text { penyelenggaraan TPA } & \\
\end{array}$ & \\
\hline 2 & $\begin{array}{l}\text { Training Of Trainer pengurus TPA } \\
\text { Pelaksanaan pelatihan akan diberikan kepada pada } \\
\text { pengurus Takmir Masjid dan pemuda yang bersedia } \\
\text { membantu kepengurusan TPA dengan bekerjasama } \\
\text { dengan BKPRMI Sleman }\end{array}$ & $\begin{array}{l}\text { Terlaksana program TO } \\
\text { dan terbentuknya pengurus } \\
\text { TPA }\end{array}$ & $\begin{array}{l}\text { Evaluasi keberlanjutan } \\
\text { program TPA }\end{array}$ \\
\hline 3 & Pelaksaan TPA secara rutin & $\begin{array}{l}\text { Terselenggaranya kegiatan } \\
\text { TPA yang }\end{array}$ & $\begin{array}{l}\text { Evaluasi keberlanjutan } \\
\text { program TPA }\end{array}$ \\
\hline
\end{tabular}

\section{Hasil dan Pembahasan}

Pelaksanaan parenting dilakukan dengan cara penyuluhan kepada warga yang direncanakan akan dilakukan selama dua kali pertemuan. Akan tetapi, parenting baru bisa terlaksana satu kali pertemuan. Proses awal dilakukan observasi terkait kondisi warga. Selanjutnya, dilakukan pretest (tes awal) untuk mengetahui pengetahuan dan pemahaman awal warga terkait cara mendidik anak dan pemahaman kesehatan keluarga. Setalah itu, dilakukan penyuluhan oleh ahli / berkompeten pada bidang parenting. Kegiatan tersebut sudah terlaksana pada tanggal 15 Maret 2020 dengan pemateri seorang psikolog (Bp M. Arif Rizqi). Kegiatan ini dihadiri sebanyak 33 orang.

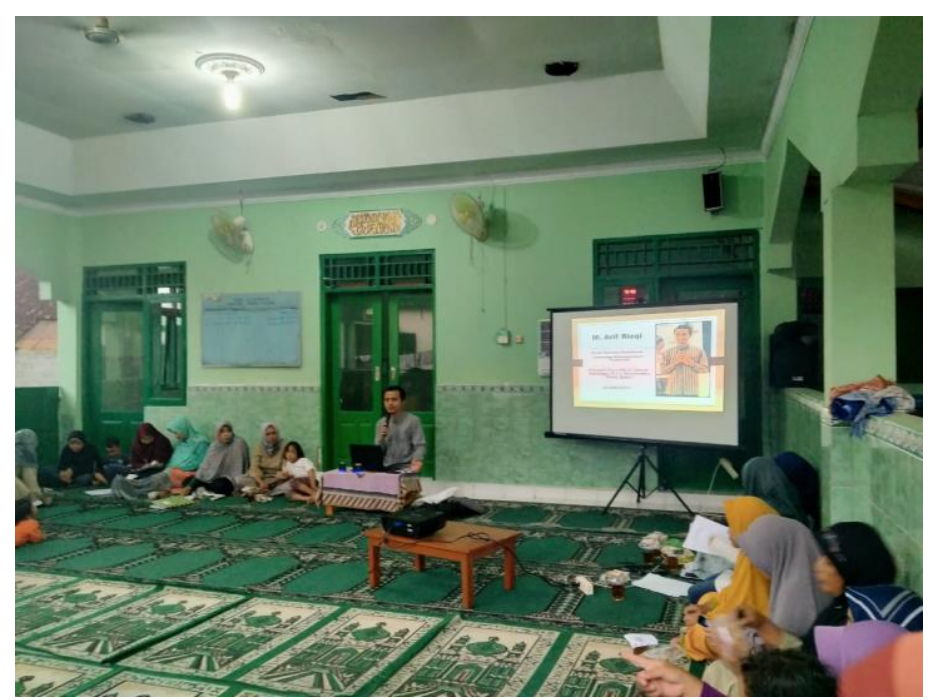

Gambar 1. Pelaksanaan program parenting oleh Psikolog M. Arif Rizqi 
Pada akhir program parenting dilakukan postest untuk melihat pemahaman dan tingkat stres dalam pengasuhan yang dialami peserta. Hasil pengujian hipotesis secara statistik menunjukkan adanya perbedaan skor stres pengasuhan antara sebelum dan sesudah pelaksanaan program (Gambar 2). Dari 33 orang yang mengikuti kegiatan, hanya 29 orang yang mengisi pretest dan postest secara penuh sehingga yang dapat dianalisis sejumlah 29 orang dengan ratarata usia 49,58 tahun.

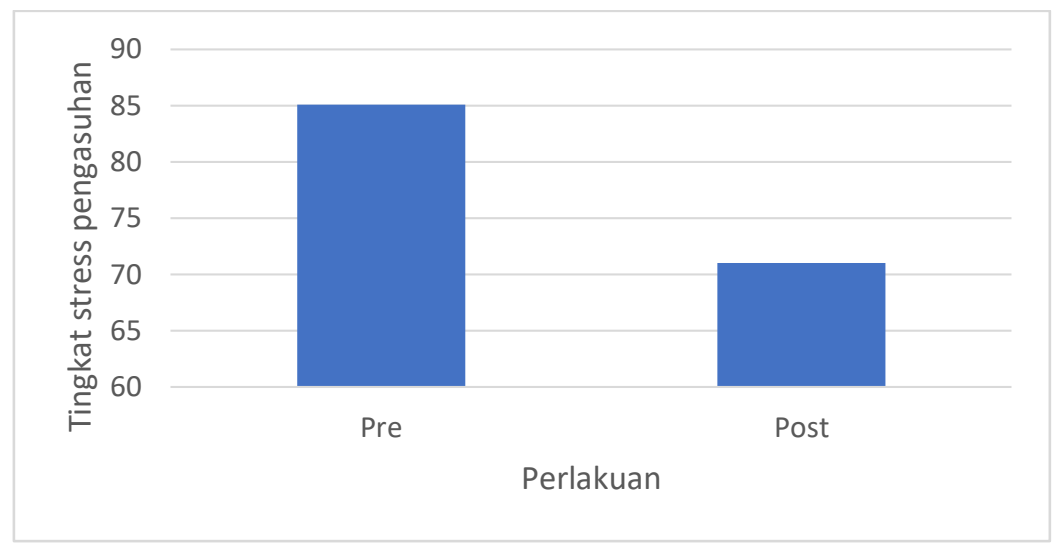

Gambar 2. Grafik rerata nilai skor stress pengasuhan.

Tabel 2. Hasil nilai pretest dan postest nilai skor stress pengasuhan

\begin{tabular}{|c|c|c|c|c|}
\hline & Min & Max & Rerata & SD \\
\hline PreTest & 81 & 88 & 85,06 & 9,95 \\
\hline PostTest & 67 & 74 & 71,03 & 10,23 \\
\hline
\end{tabular}

Hasil penelitian ini juga sesuai dengan penelitian terdahulu yang menunjukkan bahwa pendidikan pengasuhan (parenting training) mempunyai korelasi yang positif dalam menurunkan stres pengasuhan pada orang tua (Syanti dan Handadari, 2016). Program parenting juga dapat membantu orang tua dalam berkomunikasi dan berdampak baik untuk perkembangan emosi anak (Moran, Ghate, \& van der Merwe, 2004). Intervensi yang berupa program parenting disertai dengan pendekatan spiritual dapat berpengaruh terhadap interaksi positif antara orangtua dengan anak (Kurniawan dan Uyun, 2013).

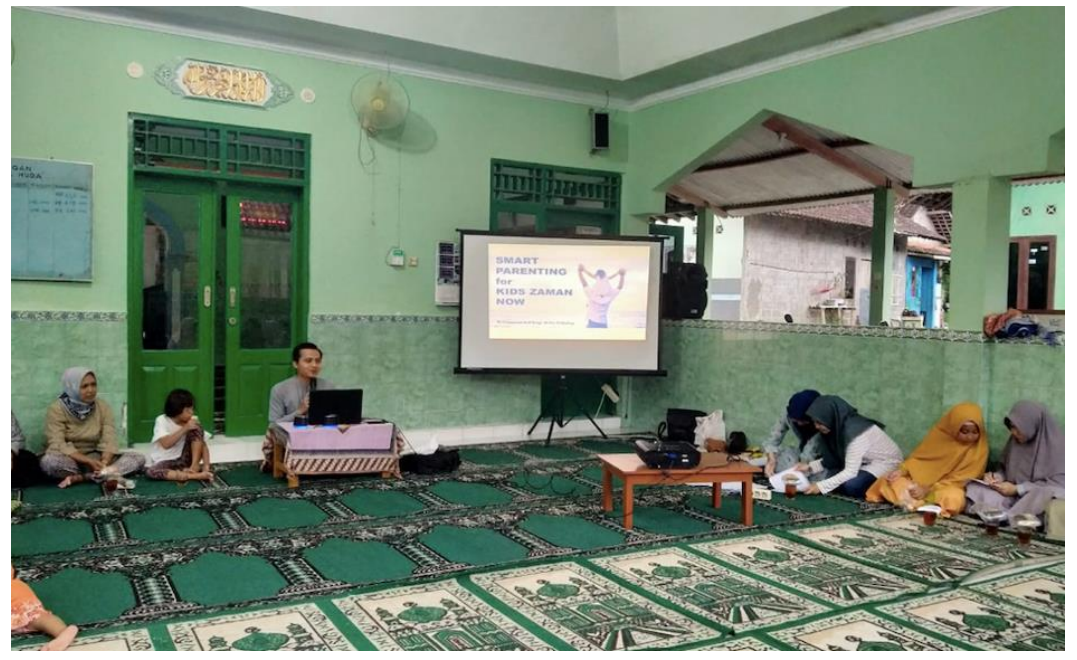

Gambar 3. Pelatihan parenting disertai dengan praktik kepada peserta 
Untuk mendukung program parenting yang sudah dilaksanakan, perlu diadakan pendirian Taman Pendidikan Alquran (TPA) pada lokasi mitra. Adanya TPA akan dapat meningkatkan nilai-nilai spiritual dari anak dan diharapkan dapat menularkan ke lingkungan keluarga masing-masing. Program pendirian TPA dimulai dengan program pelatihan kepada calon pengurus dan takmir masjid. Kegiatan ini belum terlaksana karena terkendala Covid-19 dan akan dijadwalkan ulang secara daring (online)

\section{Kesimpulan}

Program parenting dapat menurunkan tingkat strss pengasuhan pada ibu-ibu. Hal ini ditunjukkan dengan penurunan nilai skor stres pengasuhan dari 85,06 menjadi 71,03.

\section{Ucapan Terima kasih}

Ucapan terima kasih penulis sampaikan kepada LP3M UMY dalam program hibah pengabdian masyarakat tema PPDM 2020 No: 031/PEN-LP3M/I/2020, ibu-ibu PKK Dusun Polowidi, dan Takmir Masjid Darul Huda Dusun Polowidi, Timulyo, Sleman.

\section{Daftar Pustaka}

Akhyadi, Ade S dan Mulyono, Dinno. 2018. PROGRAM PARENTING DALAM MENINGKATKAN KUALITAS PENDIDIKAN KELUARGA (Program Pengabdian di Desa Karangpakuan, Kecamatan Darmaraja, Kabupaten Sumedang). Jurnal Pengabdian Kepada Masyarakat (Abdimas) IKIP Siliwangi. 1:1-8

Kurniawan, I.N dan Uyun, Q. 2013. PENURUNAN STRES PENGASUHAN ORANG TUA DAN DISFUNGSI INTERAKSI ORANG TUA-ANAK MELALUI PENDIDIKAN PENGASUHAN VERSI PENDEKATAN SPIRITUAL (PP-VPS). Jurnal Intervensi Psikologi, 5 (1): 111-130.

Moran, P., Ghate, D., \& van der Merwe, A. (2004). What works in parenting support? A review of the international evidence. Nottingham: Department for Education and Skills.

"National Association for the Education of Young Children | NAEYC TYC | Teaching Young Children Magazine". Naeyc.org. Diterbitkan 2013-03-22.

Setiadi. 2008. Konsep dan Proses Keperawatan Keluarga. Jogyakarta : Graha Ilmu

Syanti, W.R, dan Handasari W. 2016. Penerapan Behavioral Parent Training untuk Menurunkan Stres Pengasuhan pada Ibu yang Memiliki Anak dengan Gangguan ADHD. Insan, 1 (1): 57-65. 